\title{
Niobium Catalysts Beyond Pentachloride
}

a Universidade Federal do Rio de Janeiro, Instituto de Química, Avenida Athos da Silveira Ramos 149, Bloco A, $7^{\circ}$ andar, Centro de Tecnologia, Cidade Universitária, CEP 21941-909, Rio de Janeiro-RJ, Brasil.

${ }^{\mathrm{b}}$ Universidade Federal do Rio de Janeiro, Campus Macaé, Avenida Aluizio da Silva Gomes 50, Granja dos Cavaleiros, CEP 27930-560, Macaé, RJ, Brasil.

\section{^E-mail: jbarros@iq.ufrj.br}

Recebido em: 29 de Dezembro de 2020

Aceito em: 9 de Junho de 2021

Publicado online: 30 de Agosto de 2021

"This manuscript is dedicated to the memory of our dear student Leonardo Oliveira (Balotelli) victim from covid-19.

\section{Catalisadores de Nióbio Além do Pentacloreto}

Pamella M. Monte, ${ }^{a}$ Anna Paula P. M. da Silva, ${ }^{a}$ Lorena Fortes, a José C. Barros, ${ }^{a, t,}$ (1) Tiago L. da Silva

Niobium is a metal that has many uses in different areas of work, although the use of niobium compounds as Lewis acid in the field of Organic Chemistry has been increasing over the years. Niobium pentachloride is the main compound used as a catalyst in synthesis reactions. However, other $\mathrm{Nb}$ catalysts such as heterogeneous or water-soluble ones emerge as an alternative in those reactions. This article presents the use of niobium catalysts beyond pentachloride in the field of Organic Chemistry in the last ten years.

Keywords: Niobium; catalysts; organic synthesis

\section{Introduction}

Discovered in 1801, niobium is a metal whose majority of world reserves are located in Brazil (98\%), that is also responsible for $93 \%$ of world production. This metal is largely used in metal alloys, such as ferroniobium, which is applied in the automobile industry, gas and oil pipelines and airplane turbines.

In the field of Organic Chemistry, niobium pentachloride is the leading compound, employed as a Lewis acid in different reactions addressed in the literature, like Friedel-Crafts, oxidation of alcohols, Diels-Alder, epoxide ring opening, Mukayama, allylation of aldehydes and aldimines, nucleophilic additions to cyclic $N$-acyliminium ions, carboxamide synthesis, intramolecular ene, aldol and aza-aldol, multicomponent, protection and deprotection or demethylation. ${ }^{\text {1a-h }}$ It is particularly noteworthy the use of $\mathrm{NbCl}_{5}$ in the synthesis of the cytotoxic natural product $( \pm)$-bakkenolide $\mathrm{A}^{1 \mathrm{i}}$ and also in the industrial process to the forensic reactive luminol $\mathrm{l}^{1 \mathrm{j}-\mathrm{k}}$ followed by supply to the civil police of Rio de Janeiro state.

Despite several uses, $\mathrm{NbCl}_{5}$ shows a major drawback which is the reaction with moist air to produce hydrogen chloride and hydrated niobium pentoxide (niobic acid). Thus, its manipulation usually requires the use of an inert atmosphere and dry solvents. Therefore, several $\mathrm{Nb}$ catalysts emerge to substitute $\mathrm{NBCl}_{5}$ showing interesting features in catalysis such as being heterogeneous, water-soluble, recyclable or in nanometric scale.

Here, a highlight of several recent uses of niobium catalysts other than pentachloride is presented. These catalysts can be safe, easy to use, readily available, stable, and finally give rise to more sustainable reactions in organic synthesis, contributing to the expansion of chemical compounds inventory.

\section{Catalytic Potential of Nb Compounds Beyond Pentachloride}

2.1. Niobic acid, niobium phosphate and ammonium niobium oxalate for esterification and transesterification to biodiesel production

Biodiesel is a biodegradable fuel composed of a mixture of fatty acids esters. It is considered environmentally benign when compared to fossil fuels and is usually prepared by transesterification of triacylglycerol with methanol or ethanol in a basic medium. However, the use of basic conditions results in considerable degrees of saponification. Alternatively, mineral acids like $\mathrm{H}_{2} \mathrm{SO}_{4}$ or $\mathrm{HCl}$ can be used as homogeneous catalysts, but the use of these acids requires harsh conditions and results in the corrosion of equipment. To overcome these problems, the use of acid heterogeneous catalysts is strongly recommended. Recently, niobium oxide (prepared by calcination of niobic acid $\mathrm{HY}-340, \mathrm{Nb}_{2} \mathrm{O}_{5} \cdot \mathrm{nH}_{2} \mathrm{O}$ ) and watersoluble ammonium niobium oxalate $\left(\mathrm{ANO}, \mathrm{NH}_{4}\left[\mathrm{NbO}\left(\mathrm{C}_{2} \mathrm{O}_{4}\right)_{2}\left(\mathrm{H}_{2} \mathrm{O}\right)_{\mathrm{x}}\right] \cdot \mathrm{nH}_{2} \mathrm{O}\right)$ were employed 
as catalysts to prepare biodiesel from sunflower, canola, corn, soybean or linseed by transesterification with methanol or ethanol, under reflux or ultrasound. For the oxide, the best conversion obtained was $60 \%$ using canola oil and methanol, while for the ANO the best results were $70 \%$ (reflux for $48 \mathrm{~h}$ ) and $43 \%$ (ultrasound for $4 \mathrm{~h}$ ) of conversion obtained with soybean and ethanol (Scheme 1a). ${ }^{2 a}$ The catalytic pathway to obtain biodiesel is based on transesterification of the triacylglycerol (TAG) and involves activation of triacylglycerol carbonyl followed by nucleophilic attack of the alcohol, prototropism, elimination of diacylglycerol (DAG) and finally restoring of the carbonyl and the catalyst. The other two transesterifications result in glycerol and a mixture of fatty acid esters - biodiesel (Scheme 1b). The pyridine adsorption by Fourier Transform Infrared (FTIR) analysis and the surface area by Brunauer-Emmett-Teller (BET) analysis indicated that niobium oxides showed Lewis acid sites (LAS) and Brønsted acid sites (BAS) as well.

Niobic acid $\left(\mathrm{Nb}_{2} \mathrm{O}_{5} \cdot \mathrm{nH}_{2} \mathrm{O}\right)$ and niobium phosphate $\left(\mathrm{NbOPO}_{4}\right)$ were tested as catalysts in the esterification reaction of fatty acids with alcohols under reflux conditions. Different aspects of the reaction were evaluated, such as catalytic activity from niobium oxide, alcohols, carbonchain length from fatty acid, temperature and reaction time. In a first approach, the catalytic activity was analyzed in the esterification of lauric acid with butanol. Niobium phosphate showed higher acid conversion than niobic acid. Thus, using niobium phosphate $(10 \% \mathrm{w} / \mathrm{w})$, methanol, ethanol and butanol were evaluated in the esterification of lauric acid. The best result was obtained with butanol $(81 \%$ of acid conversion after $4 \mathrm{~h}$ of reaction at a temperature below the boiling point of the alcohol). This alcohol is not usually used in the esterification reaction of fatty acids to produce biodiesel, thereby this result was attributed to the higher reaction temperature. Three saturated and one unsaturated fatty acids were evaluated in the esterification with butanol and good to excellent conversion was observed under the same reactional conditions (Table 1). The reaction temperature was evaluated in the reaction between lauric acid and methanol, while the reaction time was evaluated in the reaction between lauric acid and butanol. As expected, high temperature and long reaction time increased the acid conversion. The catalyst has been proven to be recyclable, keeping acid conversions at high values $(\approx 97 \%)$ even after 3 cycles (Scheme $1 \mathrm{c}$ ). ${ }^{3 \mathrm{a}}$ In all of those reactions, the alcohol/fatty acid molar ratio (MR) was $10 / 1$. An evaluation of different aspects of palm fatty acids esterification by heterogeneous acid catalysts, such as alcohol/ fatty acid molar ratio (methanol or ethanol) and catalyst concentration indicated that the catalyst concentration is the most influent on reaction conversion, followed by alcohol/ fatty acid molar ratio. ${ }^{3 b}$

Table 1. Conversion of fatty acids with butanol under niobium phosphate catalysis $^{\mathrm{a}}$

\begin{tabular}{cc}
\hline Fatty acid & Conversion by ${ }^{\mathbf{1}}$ NMR (\%) \\
\hline Lauric Acid / C12:0 & 97 \\
Myristic Acid / C14:0 & 97 \\
Stearic Acid / C20:0 & 94 \\
Oleic Acid/ C18:1 cis-9 & 85 \\
\hline
\end{tabular}

${ }^{a}$ Adapted from ref ${ }^{3 a}$

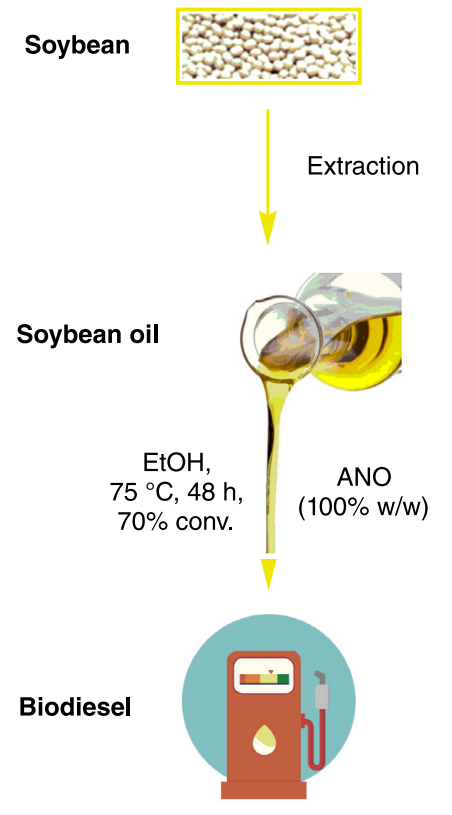

a

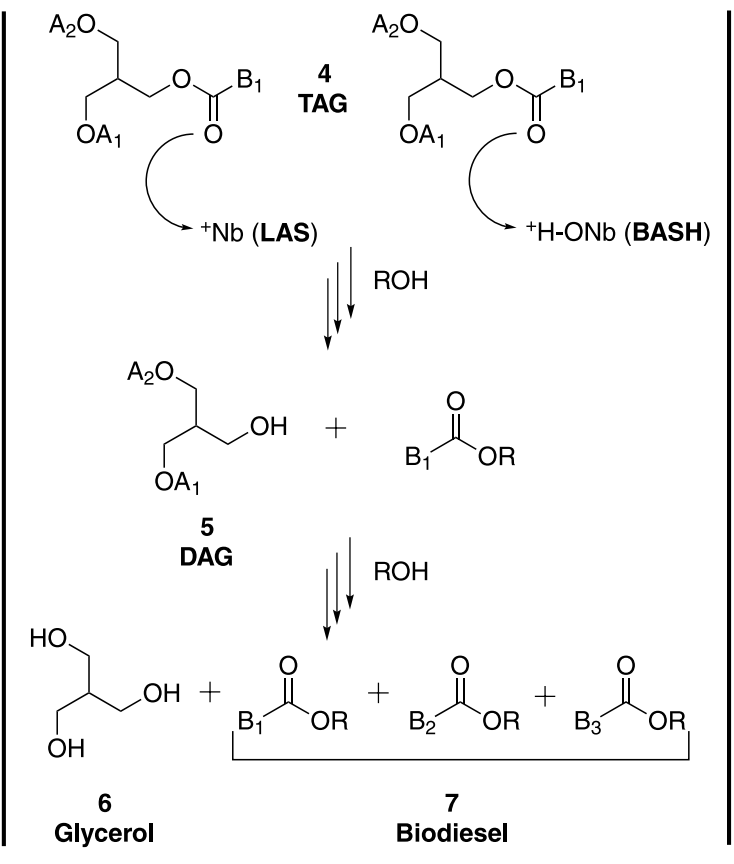

b
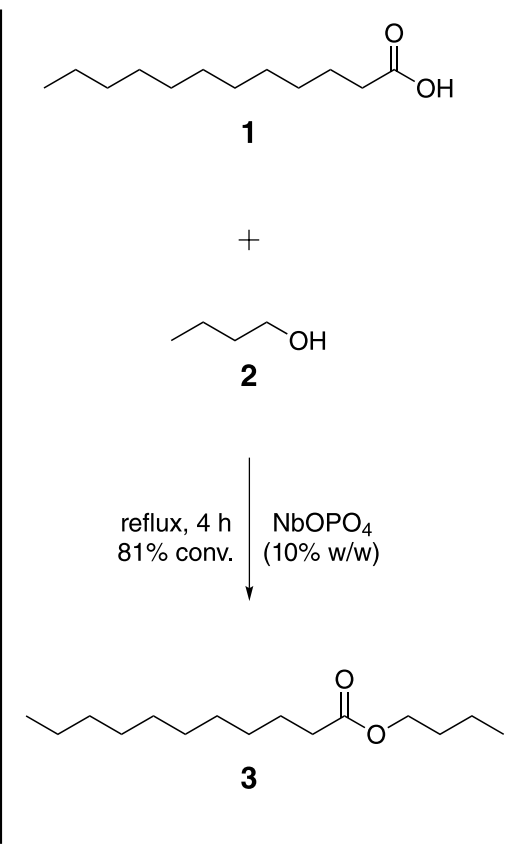

c

Scheme 1. a) Production of biodiesel from soybean and ethanol (Image source: adapted from ref ${ }^{2 \mathrm{~b}-\mathrm{c}}$ ).

b) Biodiesel preparation showing Lewis/Brønsted acid sites of the catalyst. c) Esterification of fatty acids 
2.2. ( $\alpha$-Diimine) niobium trichloride complex for hydrodehalogenation

Hydrodehalogenation is the replacement of a halogen atom by a hydrogen atom in an organic compound. This method allows for the decomposition of toxic organic halides that have a high resistance to degrade under ambient conditions. Current approaches to hydrodehalogenation are based on the use of alkaline metals, alkaline earth metals or their organometallic reagents in presence of organic or inorganic hydrogen sources, but they generate a stoichiometric amount of metal salt. As a metal-salt free alternative, organotin hydrides like $n \mathrm{Bu}_{3} \mathrm{SnH}$ in presence of a radical initiator are employed, but both organotin hydrides and reaction by-products (like $n \mathrm{Bu}_{3} \mathrm{SnX}$ ) are toxic. Environmentally acceptable alternatives require the use of precious metal heterogeneous catalysts in the presence of hydrogen gas, but catalyst are still expensive, and non-expensive metal sources are needed. A niobium complex bearing a redox-active $\alpha$-diimine ligand was employed in the hydrodehalogenation reaction of alkyl halides in the presence of $\mathrm{PhSiH}_{3}$. In a first moment, reactions between 1,1,1,3-tetrachloropropane and different silanes were performed with $3 \mathrm{~mol} \%$ of ( $\alpha$-diimine) $\mathrm{NbCl}_{3}$ as the catalyst and deuterated benzene as solvent at $120^{\circ} \mathrm{C}$ for $2 \mathrm{~h}$. The best result was obtained with 1 equivalent of $\mathrm{PhSiH}_{3}$ as hydrogen source (85\% yield). These reactions conditions were expanded to other alkyl halides, such as dibromomethane and benzyl bromide derivatives and most reactions showed satisfactory yields after $14 \mathrm{~h}$ of reaction. Besides being used as a hydrogen source, $\mathrm{PhSiH}_{3}$ also behaves as a reductant to prepare the tetrachloroniobium complex used as a catalyst in the hydrodehalogenation reaction. The mechanism is thought to proceed in a radical fashion, in which the haloalkane transfer a halogen radical to the $\mathrm{Nb}$ complex, the $\alpha$-diimine allowed the $\mathrm{Nb}$-complex to switch its coordination mode from a dianionic folded form to a monoanionic planar one, and finally hydrogen radical is abstracted from $\mathrm{PhSiH}_{3}$ (rate-determining step) to generate the form of a dehalogenated product (Scheme 2). When compared to $\mathrm{NbCl}_{3}$, the ( $\alpha$-Diimine) niobium trichloride complex was proven to be superior and more selective in hydrodehalogenation. ${ }^{4 a}$ Additionally, $\mathrm{NbCl}_{5}$ was already reported in the hydrodehalogenation of $\mathrm{CF}_{3}$ to afford $\mathrm{CH}_{3}$ groups. $^{4 b}$

\subsection{Niobium phosphates and Nb-Al-SBA-15 for Friedel- Crafts alkylation}

The reaction between benzene/toluene and benzyl chloride/benzyl alcohol is of great importance for producing dielectric fluids, pharmaceutical intermediates and chemicals. Moreover, the use of heterogeneous catalysts is relevant as they can be easily separated from the reaction<smiles>ClCCCC(Cl)(Cl)Cl</smiles>

8

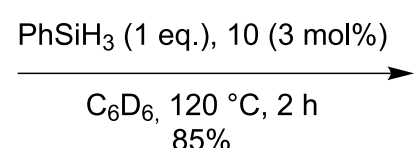
$85 \%$<smiles>ClCCCC(Cl)Cl</smiles>

9

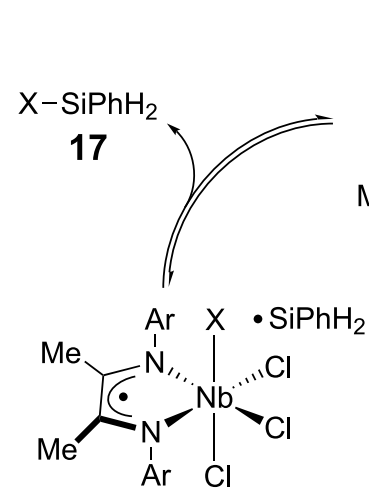

16

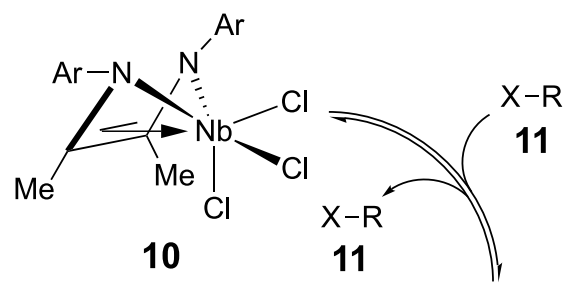

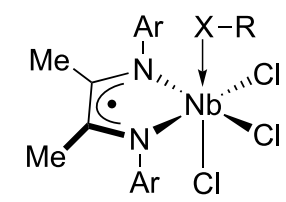

12

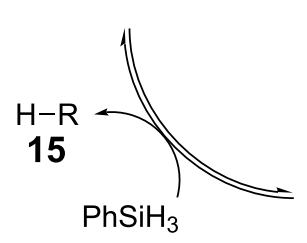

14

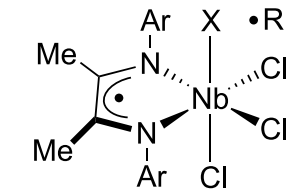

13

Scheme 2. Hydrodehalogenation of an alkyl halide and intermediate scheme 


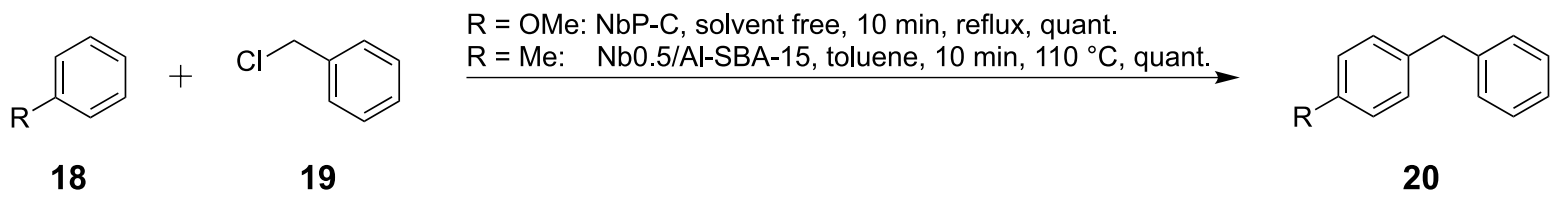

Scheme 3. Alkylation of anisole or toluene with benzyl chloride

medium and recycled. The benzylation of anisole $(\mathrm{R}=\mathrm{OMe}$, Scheme 3) with benzyl chloride using different niobium phosphates catalysts was investigated by the authors. Three catalysts were studied: a commercial calcined (NbP-C), a commercial calcined recrystallized (NbP-R) and a crystalline prepared from an HF route (NbP-S). All reactions were carried out with anisole/alkylating agent molar ratio of $15 / 1$ ( $150 \mathrm{mmol}, 16.2 \mathrm{~g}$ of anisole), phenol/alcohol molar ratio of $10 / 1$ and $250 \mathrm{mg}$ of the catalyst under reflux conditions for different reactions time. Additionally, niobium phosphate was calcined in an oven $\left(400-500^{\circ} \mathrm{C}\right)$ under static air for $2 \mathrm{~h}$ before it was used. The conversion of benzyl chloride was almost quantitative in all cases, although it was noticed that the reaction using the crystalline catalyst was carried out slowly. The selectivity of these reactions was also studied and the conversion to the monobenzylation product was superior to $90 \%$ in all cases. ${ }^{5}$

In another approach, SBA-15 aluminosilicates with different niobium metal loadings $(0.5$ and $1 \mathrm{wt} \%)$ were mechanochemically prepared as catalysts to study the influence of niobium in the acid properties of the material. Characterization techniques such as BET, Diffuse Reflectance Infrared Fourier Transform (DRIFT) spectroscopy of Pyridine-adsorption, and Inductively Coupled Plasma Mass Spectroscopy (ICP-MS) indicated that materials preserved textural and structural properties despite the niobium incorporation.

The influence of niobium as Lewis acidity in composite was investigated in the alkylation of toluene $(\mathrm{R}=\mathrm{Me}$, Scheme 3) with benzyl chloride, while Brønsted acid activity was evaluated using benzyl alcohol instead. The results indicated that the incorporation of niobium resulted in a slight increase in Lewis acidity showing quantitative conversion in the reaction time (>10 min) in the alkylation of toluene with the benzyl chloride, but the incorporation did not influence the Brønsted acidity as alkylation with benzyl alcohol remained unchanged when compared to pure SBA-15 aluminosilicate. ${ }^{6}$

\subsection{Niobium oxides for Biginelli reaction}

Dihydropyrimidinones (DHPMs) are important structures in medicinal chemistry as they show activities like calcium blockers, antibacterial, antifungal, antiviral, anticancer or antihypertensive. ${ }^{7}$ They are prepared by the Biginelli reaction, a multicomponent reaction among aldehydes, urea and a $\beta$-ketoester. Heterogeneous catalysts based on niobium oxide (HY-340, HY-340/T, $\mathrm{Nb}_{2} \mathrm{O}_{5}, \mathrm{Nb}_{2} \mathrm{O}_{5} / \mathrm{T}$, where $\mathrm{T}$ represents calcination) were investigated as catalysts in this reaction. Initially, the physicochemical properties of these materials were investigated by Scanning Electron Microscopy (SEM), High-Resolution Transmission Electron Microscopy (HRTEM), Infrared Spectroscopy (FTIR), X-ray diffraction (XRD), thermogravimetric analysis and $\mathrm{N}_{2}$ adsorption/ desorption measurements. The characterizations showed that catalyst of niobium oxides have high crystallinity and large surface area. The Biginelli reactions showed that the $\mathrm{Nb}_{2} \mathrm{O}_{5} / \mathrm{T}$ catalyst performed the best result without solvent and under a short reaction time (38 $\mathrm{min}$ ) achieving a product yield of $94 \%$. The methodology was expanded to several aldehydes, but the yields were lower, and urea can be substituted by thiourea. It was observed that the catalyst can be reused for three cycles in the reaction without compromising the reaction yield. ${ }^{\text {a }}$

Although Biginelli reactions could pass through three main mechanisms: iminium, enamine, and Knoevenagel, the acidic catalysts like niobium compounds usually results in the Knoevenagel one ${ }^{7 b}$. Thus, the catalytic cycle begins with carbonyl activation by the acid catalyst, followed by the attack of the tautomeric enol form of methyl acetoacetate. The adduct formed with catalyst eliminates water and is attacked by urea, and intramolecular attack from the second nitrogen atom afford the target heterocycle after dehydration and dissociation of catalyst which can be recycled (Scheme 4).

\subsection{Niobic acid and niobium oxides for the preparation of dimethoxymethane}

Dimethoxymethane (DMM) is a non-corrosive and nontoxic liquid with several uses like intermediates or solvent in pharmaceutical and perfume industries, and additive in fuels like diesel. The modification of a niobium catalyst to make the methanol oxidation process to dimethoxymethane more economically viable by producing it in a single step under mild conditions compared with the literature was observed in this work. The modification of a commercial catalyst was obtained by treatment of commercial HY$340\left(\mathrm{Nb}_{2} \mathrm{O}_{5}\right)$ with sulfuric acid or $p$-toluenesulfonic acid. The best catalytic activity observed was a methanol conversion above $80 \%$ with DMM selectivity values close to $100 \%$ for $300 \mathrm{~min}$ at $100{ }^{\circ} \mathrm{C}$ using less than $1 \mathrm{wt} \%$ catalyst and $10 \mathrm{wt} \%$ hydrogen peroxide. Moreover, the better performance of these functionalized materials of niobium may be justified by the presence of sulfate groups observed by X-ray Photoelectron Spectroscopy (XPS), Temperature Programmed Reduction (TPR), ammonia 
<smiles>O=Cc1ccccc1</smiles>

21<smiles>COC(=O)CC(C)=O</smiles>

22<smiles>NC(N)=O</smiles>

23<smiles>COC(=O)C1=C(C)NC(=O)NC1c1ccccc1</smiles>

24

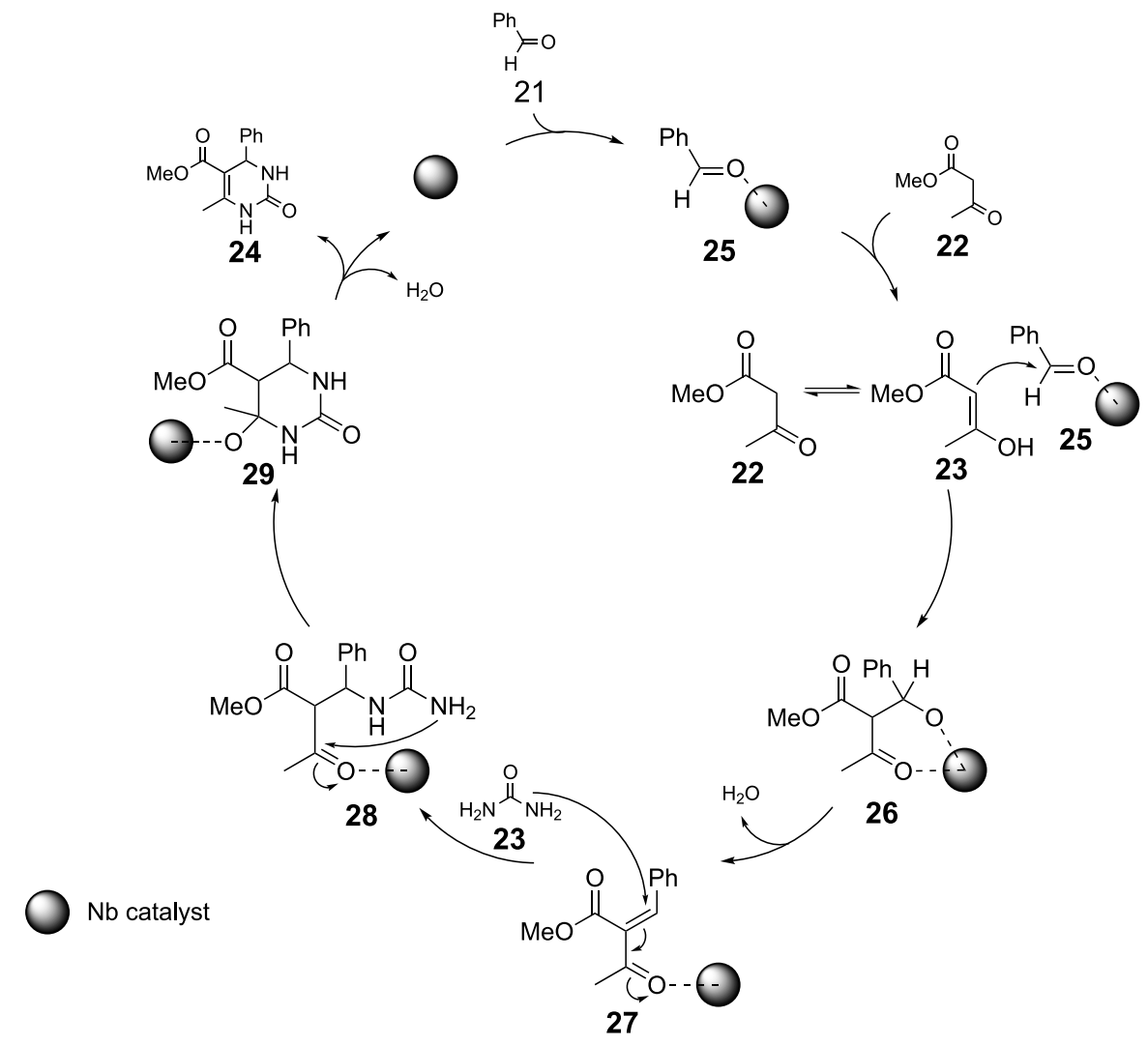

Scheme 4. Preparation of a dihydropyrimidinone and catalytic cycle

Temperature Programmed Desorption $\left(\mathrm{NH}_{3}-\mathrm{TPD}\right)$ and DRIFT of Py techniques. Sulfate groups showed an increase in acidity promoting an improvement in the catalyst and generating greater efficiency in the conversion of methanol and selectivity of DMM (Scheme 5) ${ }^{8}$ In the reaction mechanism, acidic $\mathrm{Nb}$ species show two roles. The first one is to react with hydrogen peroxide to form hydrosuperoxo species (Equation 1), while the second is trapping of superoxo $\mathrm{O}_{2}^{-\cdot}$ (and peroxo $\mathrm{O}_{2}{ }^{2-}$ ) species to produce hydroxyl radicals $\left({ }^{\circ} \mathrm{OH}\right)$ (Equation 2$)$ and trapping of superoxo species to shift equilibrium right (Equation 3). The dehydrogenation of methanol is affected by the hydroxyl radical formed from $\mathrm{H}_{2} \mathrm{O}_{2}$ to afford formaldehyde, which further reacts to afford the target DMM (Equations 4 and 5).

$$
\begin{aligned}
& \mathrm{H}_{2} \mathrm{O}_{2}(a q)+\mathrm{Nb}-\mathrm{OH}(s) \rightarrow \mathrm{HO}^{-}(a q)+\mathrm{Nb}-\mathrm{OH}_{2}^{+}(s) \\
& \mathrm{H}_{2} \mathrm{O}_{2}(a q)+\mathrm{HO}_{2}^{-}(a q) \rightarrow \cdot \mathrm{OH}(a q)+\mathrm{O}_{2}^{-\cdot}(a q)+\mathrm{H}_{2} \mathrm{O}(l) \\
& \mathrm{O}_{2}^{-\cdot}(a q)+\mathrm{Nb}(\mathrm{V})(s) \rightarrow \mathrm{Nb}(\mathrm{V})-\mathrm{O}_{2}^{-\cdot}(s)
\end{aligned}
$$

$$
\mathrm{CH}_{3} \mathrm{OH}(a q)+2 \cdot \mathrm{OH}(a q) \rightarrow \mathrm{CH}_{2} \mathrm{O}(a q)+2 \mathrm{H}_{2} \mathrm{O}(l)
$$

$\mathrm{CH}_{3} \mathrm{OH}(a q)+2 \cdot \mathrm{OH}(a q) \stackrel{-2 \mathrm{H}_{2} \mathrm{O}}{\rightarrow} \mathrm{CH}_{2} \mathrm{O}(l)+2 \mathrm{CH}_{3} \mathrm{OH}(l) \rightarrow$ $\mathrm{CH}_{3} \mathrm{OCH}_{2} \mathrm{OCH}_{3}(l)+\mathrm{H}_{2} \mathrm{O}(l)$

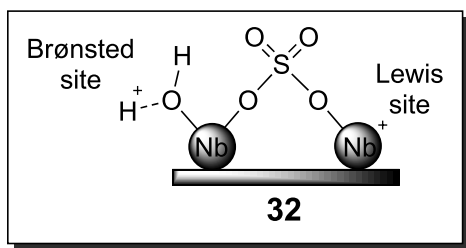

Scheme 5. Preparation of dimethoxymethane and $\mathrm{Nb}$ catalyst 


\subsection{Niobium carbene for Ring-Closing Metathesis}

Ring-Closing Metathesis (RCM) is a powerful reaction in organic chemistry, which allows for the preparation of heterocyclic, polycyclic, medium, and finally macrocyclic rings. These reactions are usually conducted through molybdenum and ruthenium-based catalysts. However, tantalum and niobium ones have already been reported in the '70s. Now, niobium catalysts were employed in the RCM of diallylic compounds affording high yields. Starting from $N, N$-diallyl- $p$-toluenesulfonamide as a model reaction, using $\mathrm{Zn}$ as co-catalyst, $\mathrm{TMSCl}$ to activate zinc and benzyl dichloride to generate carbenes, the new study screened several niobium compounds like $\mathrm{NbCl}_{5}$, $\mathrm{NbCl}_{4}(\mathrm{THF})_{2}, \mathrm{NbCl}_{3}(\mathrm{DME})$, and $\mathrm{Nb}(\mathrm{OEt})_{5}$ as precursors to metathesis catalysts resulting in excellent yields. The expansion of the methodology to other allyl-tosylates resulted in the respective pyrrolines in good yields. Upon use of allyl analogs, six or even seven-member analogs of pyrrolines can also be obtained, though bulky substituted allyl groups in both sides prevented the reaction. The reaction mechanism is thought to proceed firstly by the generation of low valent niobium species aided by zinc. Then benzyl dichloride reacts with zinc to form an organozinc, which further reacted with the niobium species to afford the niobium alkylidene catalyst and stilbene as a by-product. From the Nb-alkylidene complex, the RCM reaction proceeded in a usual way to afford the pyrroline (Scheme 6). This study represents a platform for the generation of niobium catalyst from simple precursors and uses in RCM, while the compounds were obtained in excellent yields. These reactions were specific to $\mathrm{Nb}$ as $\mathrm{Ti}$, Ta and Fe did not result in products. ${ }^{9}$

\subsection{Bis- $N$-heterocyclic carbenes niobium complex for preparation of cyclic carbonates}

Carbon dioxide $\left(\mathrm{CO}_{2}\right)$ is the main greenhouse gas, so its fixation is an important environmental subject. $\mathrm{CO}_{2}$ is also a non-expensive, nontoxic, and readily available $\mathrm{C} 1$ building block that can be used to prepare cyclic carbonates for use as solvent, but this reaction requires a catalyst. A bis- $N$-heterocyclic carbene niobium complex was prepared by the reaction between 1,3-dimesitylimidazol-2-ylidene (IMes) and $\mathrm{NbCl}_{5}$ and was obtained as red crystals which were characterized by X-ray crystallography. The bisNHC-Nb complex was employed in the reaction between $\mathrm{CO}_{2}$ and 1,2-propylene oxide at mild conditions (room temperature and pressure of $1 \mathrm{MPa}$ of $\mathrm{CO}_{2}$ for $10 \mathrm{~h}$ ). Deuterated dichloromethane was used as solvent allowing for ${ }^{1} \mathrm{H}$ NMR monitoring, and the results revealed a low yield $(16 \%)$. The reaction mechanism is based on the insertion of the propylene oxide into the metal-NHC to afford a free $\mathrm{NHC}$ and propylene oxide complexed to the metal. Then an attack of free NHC results in ring-opening, the charged oxygen attacks the $\mathrm{CO}_{2}$-carbonyl, and finally, upon attaching of the other charged oxygen for the carbonate, a cyclization occurs furnishing a cyclic carbonate and regenerating the catalyst (Scheme 7). ${ }^{10}$

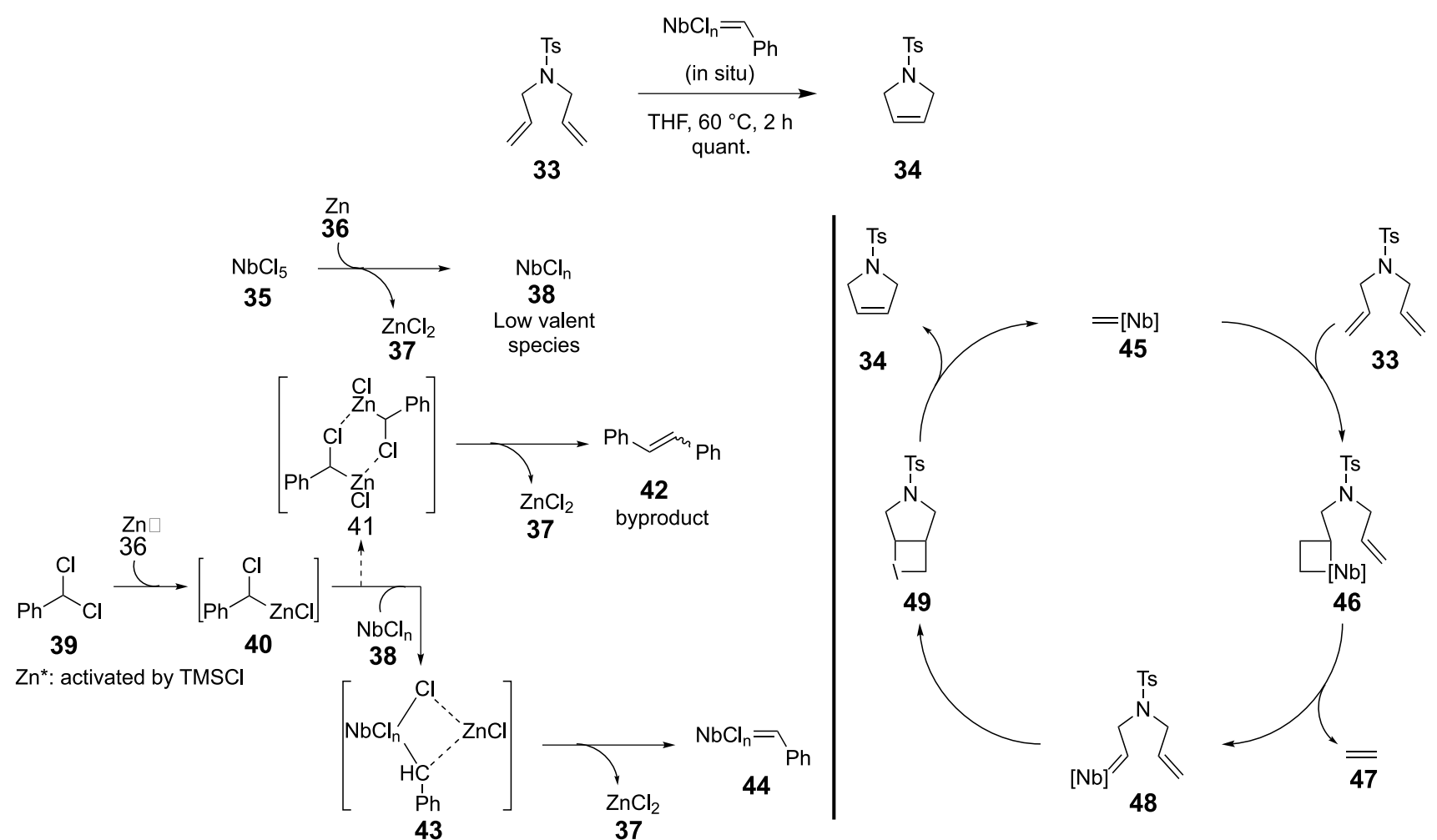

Scheme 6. Preparation of a pyrroline and catalytic cycle 


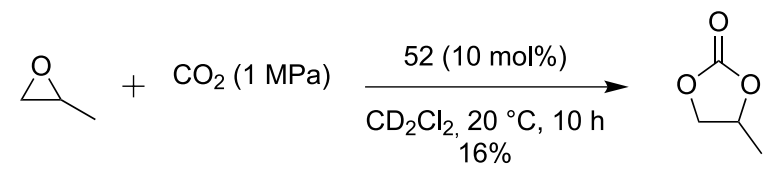

50

51

53

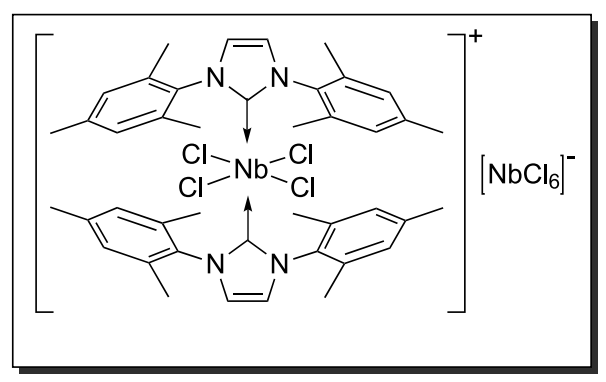

IMes $=\operatorname{Mes}^{-\mathrm{N}^{\mathrm{N}}} \stackrel{\mathrm{N} \text { Mes }}{ }$

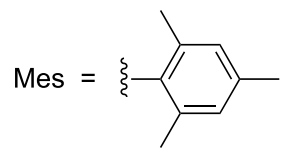

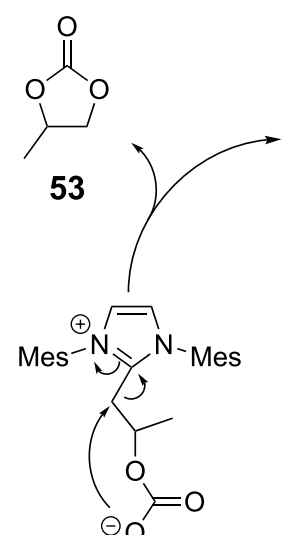
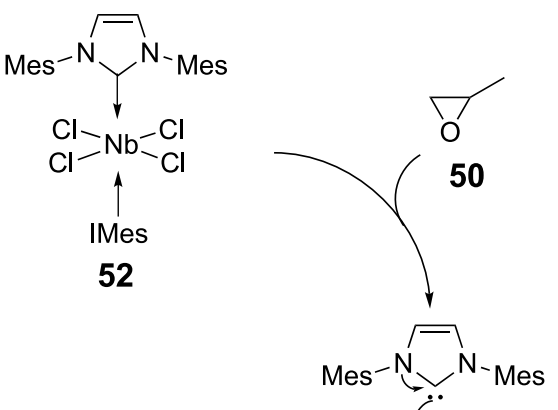

54

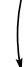

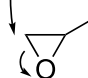

$\stackrel{\mathrm{Cl}}{\mathrm{Cl}}=\underset{\mathrm{N}}{\mathrm{N}=}-\mathrm{Cl}$

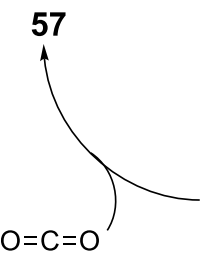

51

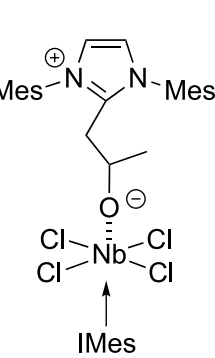

56

Scheme 7. Preparation of a carbonate and catalytic cycle

\subsection{Ammonium niobium oxalate for preparation of bis(indolyl)methanes}

Bis(indolyl)methanes (BIMs) show different biological and pharmacological activities, such as antifungal, antiinflammatory, and antibiotic. Recently, this class of compounds exhibited anticancer activity. There are many methods in the literature to prepare BIMs. However, they have a high environmental impact, such as the use of toxic reagents. A method using water-soluble ammonium niobium oxalate (ANO) to prepare bis(indolyl)methanes from indoles and carbonyl compounds under green reaction conditions were described for the first time. The initial studies focused on the development of reaction conditions. The amount of catalyst, the temperature and the reaction time were analyzed, and the best result was obtained in the reaction with $5 \mathrm{~mol} \%$ of ANO as catalyst at $50{ }^{\circ} \mathrm{C}$ for $2 \mathrm{~h}$ under conventional heating ( $97 \%$ yield). ANO is also recognized as a precursor to synthesized niobium oxide, therefore $\mathrm{Nb}_{2} \mathrm{O}_{5}$ was also tested in this reaction, but the result was unsatisfactory (12\% yield). This reaction was also performed with ultrasound irradiation using glycerol as solvent for $3 \mathrm{~min}$ at $110{ }^{\circ} \mathrm{C}$ using $5 \mathrm{~mol} \%$ of ANO (99\% conversion). Niobium oxide was also tested in the reaction with ultrasound irradiation, but the conversion results were not satisfactory. Finally, the optimized conditions in water and glycerol were used in the reaction with different indoles and aromatic aldehydes. The conversion obtained in both of those solvents was high and similar in most cases. The reuse of ammonium niobium oxalate was studied as well. In water, the catalyst can be used up to 5 times with good results, but in glycerol the catalyst was inactive after the first reaction (Scheme 8). ${ }^{11}$

\subsection{Niobium oxalate hydrate for amide bond formation}

Amide bond formation is one of the most important reactions in organic chemistry as it is involved in $25 \%$<smiles>O=Cc1ccccc1</smiles>

21

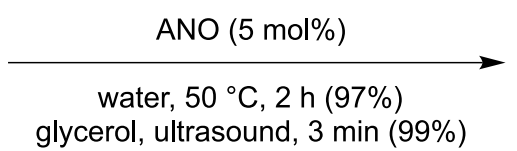<smiles>c1ccc(C(c2c[nH]c3ccccc23)c2c[nH]c3ccccc23)cc1</smiles>

59

Scheme 8. Synthesis of a bis(indolyl)methane 
of existing drugs. Most of the methods to obtain amides of pharmaceutical interest are based on the preparation of derivatives like acid chlorides or on the use of peptide coupling reagents. A new method to produce amides directly from carboxylic acids and amines using the watercompatible niobium oxalate hydrate as a catalyst was developed. Initially, the importance of this catalyst was revealed from testing several ones in the reaction between benzoic acid and phenethylamine using toluene as solvent and a Dean-Stark. After finding the best catalyst and molar ratio (1 mol\%), the methodology was expanded to several carboxylic acids like aliphatic and substituted benzoic acids. The results were obtained in good yields, except for heteroaromatic carboxylic acids. For the amine counterpart, poor nucleophilic amines like anilines required a large excess of 4 equivalents. Inspired by the absence of a reaction between oxalic acid and amines, the group proposed that the oxalate role in this reaction is also of a ligand in the amide formation. The proposed reaction scheme is based on the replacement of one oxalic by the carboxylic acid, followed by a nucleophilic attack of the amine to form a tetrahedral intermediate, liberation of the amide product, and finally, another ligand exchange to recover the catalyst (Scheme 9). This mechanism corroborates the requirement of excess of amines if poor nucleophiles. This method is workable to a variety of substrates with yields higher than $85 \%$, it is operationally simple and potentially scalable and highlights the role of oxalate as a ligand in the formation of amides. ${ }^{12}$

\subsection{Hydrophobic niobium oxyhydroxide for oxidation}

Cyclohexene oxide is an important synthetic intermediate employed in fine chemicals, polyethers and the manufacture of adipic acid. A new niobium oxyhydroxide $\left(\mathrm{NbO}_{2} \mathrm{OH}\right)$, presenting hydrophobic characteristics, was developed to catalyze the oxidation of cyclohexene to its cyclohexene oxide in a liquid-liquid biphasic process. A hydrophilic $\mathrm{NbO}_{2} \mathrm{OH}$ was prepared by reaction between ammonium niobium oxide (ANO) and $\mathrm{NaOH}$, while upon addition of the surfactant cetyltrimethylammonium bromide (CTAB) hydrophobic $\mathrm{NbO}_{2} \mathrm{OH}$ is obtained. The characterization suggested that the surfactant molecules are bound to the surface substituting hydroxyl groups, and that the surfactant decreases Brønsted acidity. The catalysts were then employed in the oxidation of cyclohexene with aqueous $\mathrm{H}_{2} \mathrm{O}_{2}$ in acetonitrile, and the results revealed the hydrophobic catalyst as superior to the hydrophilic one due to higher contact between the hydrophobic tail of the catalyst with nonpolar cyclohexene. Also, the presence of a hydrophobic part decreases the extent of further oxidation to a diol. Leaching was not observed indicating that the catalyst act as a heterogeneous one, and the amount of $\mathrm{H}_{2} \mathrm{O}_{2}$ increased the conversion by the formation of peroxoniobate species. The Hydrophobic niobium oxyhydroxide showed $65 \%$ of conversion of cyclohexene after $1 \mathrm{~h}$, and it can be reused 6 times without loss of activity (Scheme 10). ${ }^{13}$<smiles>O=C(O)c1ccccc1</smiles>

60<smiles>NCCc1ccccc1</smiles>

61

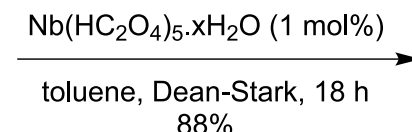

$88 \%$<smiles>O=C(NCCc1ccccc1)c1ccccc1</smiles>

62<smiles>O=C(O)C(=O)O[W]O[Na]</smiles>

63

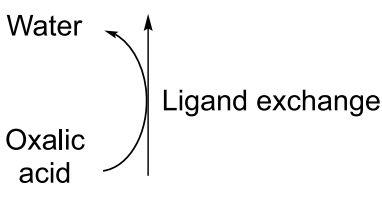

64

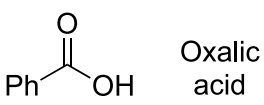

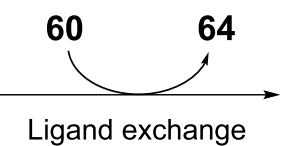

Ligand exchange

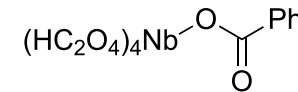

65

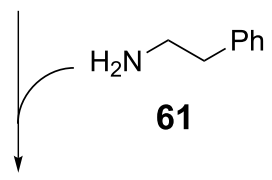

$$
\left(\mathrm{HC}_{2} \mathrm{O}_{4}\right)_{4} \mathrm{NbOH}
$$

67

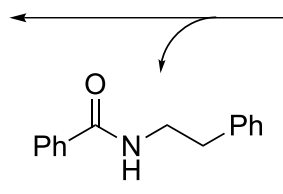

62

Scheme 9. Amide bond formation and catalytic cycle 
<smiles>C1=CCCCC1</smiles>

68

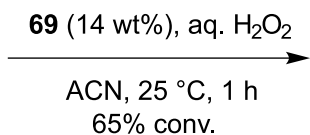

$65 \%$ conv.

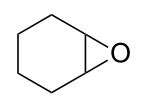

70

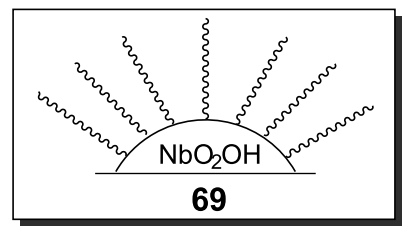

Cyclohexene

68

Epoxide

70

Scheme 10. Cyclohexene oxide formation and catalytic cycle

\subsection{Niobium oxide for rhodamine dyes}

Rhodamine derivatives are important compounds due to their photochemical and photophysical properties. Rhodamine dyes can be used in the textile industry, lasers and cytological staining. Solvent-free reactions can be more effective than conventional solution reactions because of molecular organization and proximity between molecules. Moreover, these reactions potentially reduce pollution and present lower cost. Thus, a new solvent-free synthesis of rhodamine $\mathrm{B}$ derivatives using $\mathrm{Nb}_{2} \mathrm{O}_{5}$ as catalyst was described. Aminophenol derivatives and phthalic anhydride derivatives reacted in the presence of $50 \mathrm{~mol} \% \mathrm{Nb}_{2} \mathrm{O}_{5}$ under heating for $1 \mathrm{~h}$ to obtain the desired product. All reactions resulted in high yields (over 75\%), proving the role of this catalyst as good promoter for the synthesis of rhodamine B derivatives. Furthermore, this catalyst can be recovered after the reaction and reused. The reaction mechanism is based on Friedel-Crafts acylation followed by carbonyl addition. Firstly, the anhydride carbonyl is activated by the acidic $\mathrm{Nb}$ catalyst to form the acyl ion, followed by aminophenol attack and proton transfers, resulting in a mono-acylated adduct. Then, the second aminophenol attacks the mono-acylated adduct, which upon proton transfers and lactonization affords rhodamine derivatives (Scheme 11). ${ }^{14}$

\subsection{Mixed palladium- and niobic acid-on-carbon for} $N$-benzyl deprotection

Benzyl protective groups are widely used to preserve amines and alcohols, whose deprotection reactions can occur in a variety of ways. The hydrogenation catalyzed by $\mathrm{Pd} / \mathrm{C}$ is the major strategy for deprotection of $N$-benzyl groups as it is easy to obtain the catalysts after the reactions and reuse them. However, these reactions suffer from the coordination of amines to Pd, so high temperatures, pressures and the use of acids to protonate amines are required to improve yields. Niobic acid $\left(\mathrm{Nb}_{2} \mathrm{O}_{5} \cdot \mathrm{nH}_{2} \mathrm{O}\right)$ shows Brønsted and Lewis acid properties suitable to be employed as a catalyst in these reactions. The $\mathrm{Nb}_{2} \mathrm{O}_{5} / \mathrm{C}$ was prepared from $\mathrm{NbCl}_{5}$ and activated carbon in the presence of water, obtaining $10 \% \quad \mathrm{Nb}_{2} \mathrm{O}_{5} / \mathrm{C}$. The characterization by X-Ray Diffraction (XRD) and Scanning Transmission Electron Microscopy (STEM), showed that $\mathrm{Nb}_{2} \mathrm{O}_{5}$ was supported in an amorphous form of activated carbon. The generated catalyst was employed in amine deprotection reactions together with $\mathrm{Pd} / \mathrm{C}$ varying the amines and the solvent. The best result found for $N$-benzyl dioctylamine was obtained with $1 \mathrm{~mol} \%$ of each catalyst in methanol for $45 \mathrm{~min}$ at room temperature using a balloon of $\mathrm{H}_{2}(99 \%$ yield). The mixed catalyst of $\mathrm{Nb} / \mathrm{C}$ and $\mathrm{Pd} / \mathrm{C}$ was proven to be superior to the single components. The methodology was expanded to several aliphatic, cyclic or aromatic amines in excellent yields, but unfortunately, pyridyl- or pyrimidyl- $N$-benzylamines did not react. Several $O$-benzyl and $N$-benzyloxycarbonyl $(\mathrm{Cbz})$ (including those with a pyrimidinyl-substitution) were also deprotected. The reaction was scaled up until $1 \mathrm{~g}$ of amine, and catalysts can be removed by simple filtration and recycled up to least three times without any significant loss in the catalytic activity. The leaching of $\mathrm{Pd}$ and $\mathrm{Nb}$ species was lower than $0.1 \mathrm{ppm}$ by Inductively Coupled Plasma Optical Emission Spectroscopy (ICP-OES) analysis and Inductively Coupled Plasma Mass Spectroscopy (ICP-MS). This method shows the role of niobium as a co-catalyst to perform benzyl deprotection sustainably (Scheme 12). ${ }^{15}$

\subsection{Supported niobium catalysts for photochemical degradation}

The photochemical degradation of organic compounds is a clean and efficient method for the decontamination of aquatic effluent. Niobium is widely recognized as a 
2<smiles>CNc1cccc(O)c1</smiles><smiles>O=C1OC(=O)c2ccccc21</smiles>

72

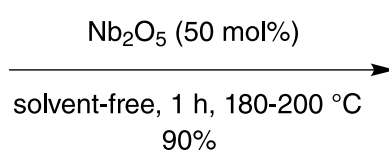

$90 \%$<smiles>CN(C)c1ccc2c(c1)Oc1cc(N(C)C)ccc1C21OC(=O)c2ccccc21</smiles>

73

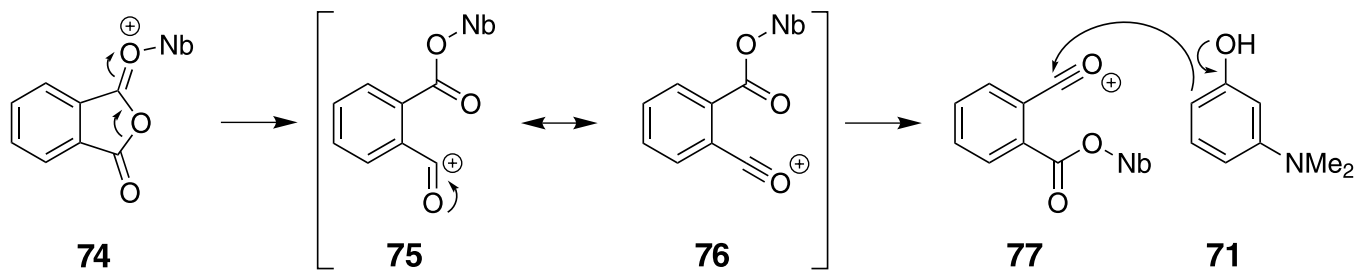

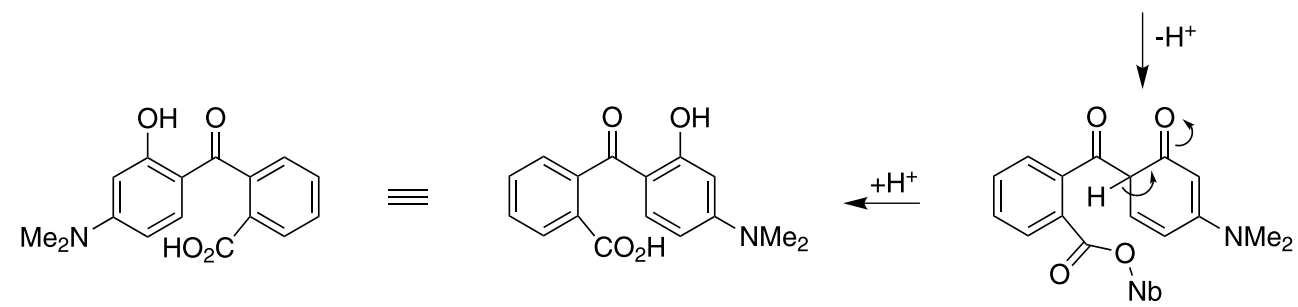

80

79

78<smiles>CN(C)c1ccc(C(=O)c2cccc(N(C)C)c2C(=O)O)c(O)c1</smiles>

81
71

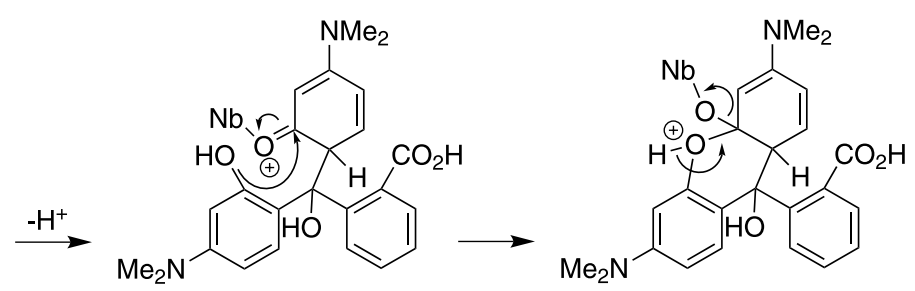

82

83<smiles>CN(C)c1ccc2c(c1)Oc1cc(N(C)C)ccc1C21OC(=O)c2ccccc21</smiles>

73

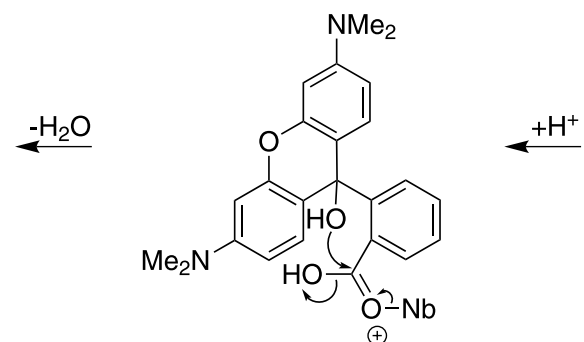

85<smiles>CN(C)c1ccc(C(O)(c2ccc(N(C)C)cc2O)c2ccccc2C(=O)O)c([O-])c1</smiles>

84

Scheme 11. Rhodamine B preparation and intermediates scheme

photocatalyst for the degradation of industrial waste from the production of synthetic intermediates, drugs, pesticides and mainly dyes. ${ }^{16}$ With Brazil as the world's fourth cotton producer $^{17}$ and niobium largest producer, these reactions are environmentally relevant.

The degradations involve the use of light energy as a driving force, a niobium catalyst and the dye to produce degradation products (DP), and several conditions like the

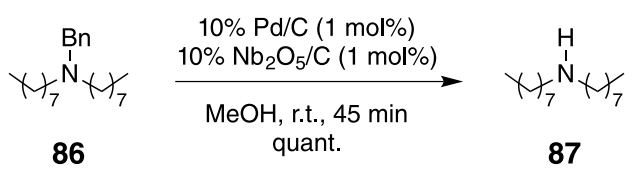

Scheme 12. $N$-benzyl deprotection

architecture of the catalysts, wavelength, $\mathrm{pH}$, temperature, among others show influence, and in general, these catalysts 


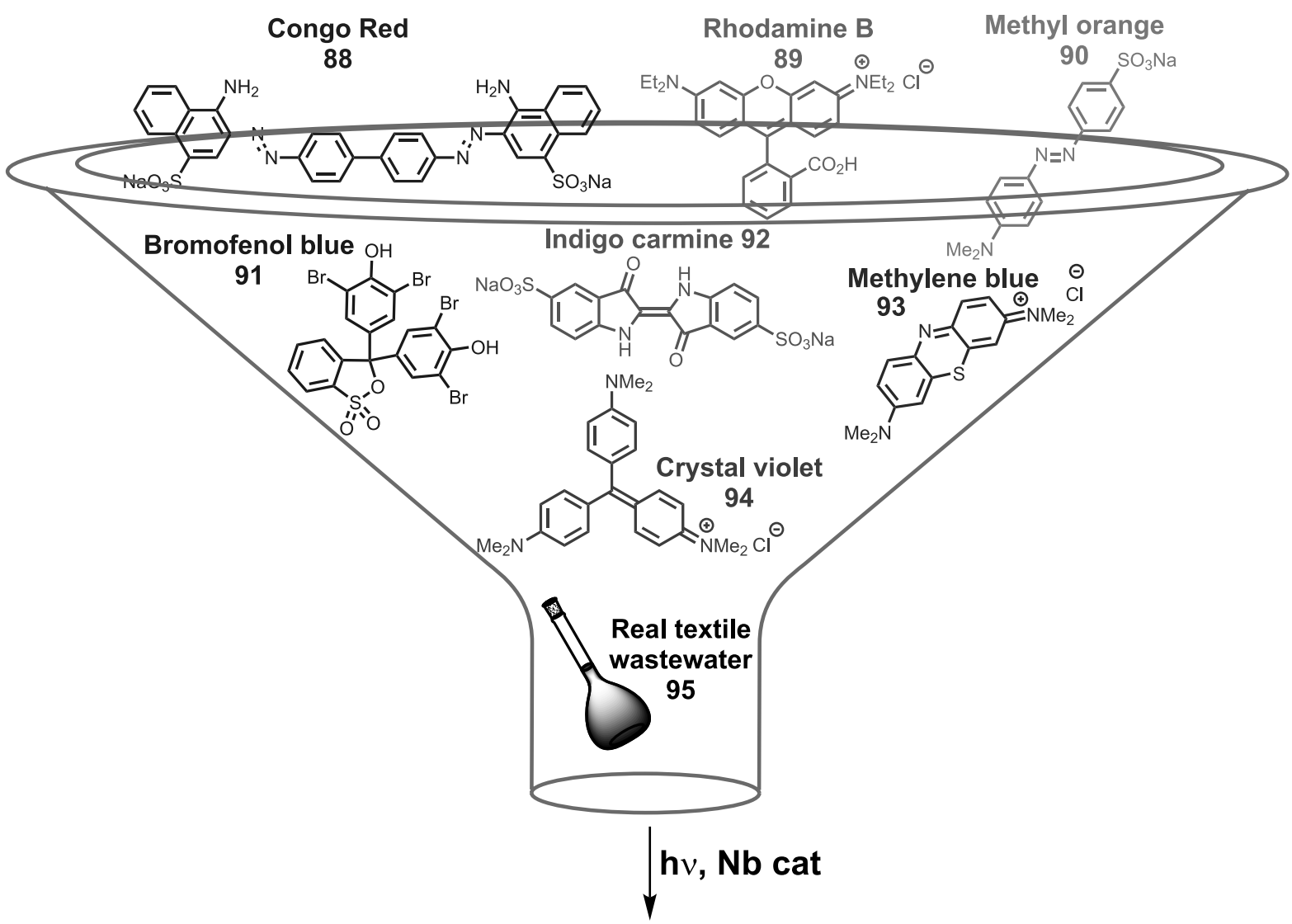

Degradation Products

Scheme 13. Dyes and waste subjected to photodegradation

Table 2. Catalysts and photodegradation conditions

\begin{tabular}{|c|c|c|c|c|c|}
\hline Dye & Catalyst & $\begin{array}{l}\text { Surface área } \\
\left(\mathrm{g}^{2} \mathrm{~m}^{-1}\right)\end{array}$ & Reaction conditions & Yield $(\%)$ & Ref \\
\hline Congo Red & $\begin{array}{l}\text { Niobium oxide anchored molybdenum } \\
\qquad(\mathrm{Nb}-\mathrm{O}-\mathrm{Mo})\end{array}$ & 5.30 & Fluorescent light $(480-570 \mathrm{~nm}), 10 \mathrm{~min}$ & 95 & 18 \\
\hline Rhodamine B & $0.3 \mathrm{wt} \% \mathrm{Nb} / \mathrm{TiO}_{2}$ nanoparticles & 200 & UV light or sunlight, $120 \mathrm{~min}$ & $>99$ & 19 \\
\hline Methyl orange & $\mathrm{Nb}_{2} \mathrm{O}_{5}$ & 200 & Sunlight, $\mathrm{H}_{2} \mathrm{O}_{2}, 40 \mathrm{~min}$ & 91 & 20 \\
\hline Bromofenol blue & $\mathrm{ZnO}-\mathrm{Nb}_{2} \mathrm{O}_{5}(50 \mathrm{ZnNb})$ & 31 & UV light, $2 \mathrm{~h}$ & 98 & 21 \\
\hline Methylene blue & $\mathrm{Nb}_{2} \mathrm{O}_{5}$ supported on mixed oxides & N/A & Sunlight, $60 \mathrm{~min}$ & 78 & 22 \\
\hline Indigo carmine & $\mathrm{TiO}_{2}-\mathrm{Nb}_{2} \mathrm{O}_{5}(5 \% \mathrm{TiNb})$ & 23 & Metallic vapor lamp (main $535 \mathrm{~nm}$ ), $2 \mathrm{~h}$ & $>99$ & 23 \\
\hline Crystal violet & $\mathrm{TiO}_{2} / \mathrm{Nb}_{2} \mathrm{O}_{5} / \mathrm{SnO}_{2} / \mathrm{RGO}^{\mathrm{a}}$ nanohybrids & 195 & Visible light, $120 \mathrm{~min}$ & 98 & 24 \\
\hline $\begin{array}{l}\text { Real textile } \\
\text { wastewater }\end{array}$ & $\mathrm{Nb}_{2} \mathrm{O}_{5}$ into carbon black (NCB-0.5) & 200 & UV-Vis, $5 \mathrm{~h}$ & $\begin{array}{l}51(\mathrm{COD})^{\mathrm{b}} \\
70(\mathrm{TOC})^{\mathrm{c}}\end{array}$ & 25 \\
\hline
\end{tabular}

${ }^{\mathrm{a}}$ RGO: reduced graphene oxide; ${ }^{\mathrm{b}} \mathrm{COD}$ : chemical oxygen demand; ${ }^{\mathrm{c}}$ TOC: total organic carbon

are recyclable (Table 2, Scheme 13). All the compounds presented in Table 2 to be used in photochemical degradation were prepared under thermal conditions. Most of them underwent a calcination process to achieve photochemical properties as photocatalyst. Catalysts cited on the table are readily available after thermal synthesis to be tested in photochemical experiment and did no required pretreatment. Nonetheless, in some cases ${ }^{18}$, the recycling tests were preceded by washing and filtration steps to avoid reagents residues and lateral products.

\section{Conclusion}

This manuscript highlighted several uses in the field of Organic Chemistry of different niobium catalysts. As a limitation of these catalysts, unlike niobium pentachloride, ANO and niobium oxide, most of the catalysts presented here are non-commercial. Nevertheless, the higher use of these non-conventional compounds and their proved activities and versatility might guarantee a place in the 
organic chemist toolbox of catalysts based on this national raw material.

\section{References}

1. For selected reviews in Nb chemistry, see: a) Marques, A. P.; Fortes, L.; Francisco, M. A. S.; Monte, P. M.; Barros, J. C.; Silva, T. L.; Niobium pentachloride $\left(\mathrm{NbCl}_{5}\right)$. Australian Journal of Chemistry 2020, 74, 219. [CrossRef]. b) Marques, A. P.; Almeida, G. C.; Barros, J. C.; Monte, P. M.; Bastos, R. O.; Monteiro, R. S.; Silva, T. L.; Ciência Hoje 2019, 356. [Link] c) Almeida, G. C.; Barros, J. C.; Monteiro, R. S.; Nióbio: o elemento do século XXI, 1st. ed., Sociedade Brasileira de Química: São Paulo, 2019. [Link] d) Bruziquesi, C. G. O.; Balena, J. G.; Pereira, M. C.; Silva, A. C.; Oliveira, L. C. A.; Nióbio: um elemento químico estratégico para o Brasil. Química Nova 2019, 42, 1184. [CrossRef] e) Arpini, B. H.; Bartolomeu, A. A.; Andrade, C. K. Z.; Lacerda, L. C. S. -F. and Lacerda Jr., $\mathrm{V}$.; Recent advances in using niobium compounds as catalysts in organic chemistry. Current Organic Synthesis 2015, 12, 570. [CrossRef] f) Lacerda Jr., V.; Santos, D. A.; Silva-Filho, L. C.; Greco, S. J.; Santos, R. B.; The growing impact of niobium in organic synthesis and catalysis. Aldrichimica Acta 2012, 45, 19. [Link] g) Andrade, C. K. Z.; Rocha, R. O.; Recent applications of niobium catalysts in Organic Synthesis. Mini-Reviews in Organic Chemistry 2006, 3, 271. [CrossRef] h) Andrade, C. K. Z.; Niobium pentachloride in Organic Synthesis: applications and perspectives. Current Organic Synthesis 2004, 1, 333. [CrossRef] i) Constantino, M. G.; Oliveira, K. T.; Polo, E. C.; Silva, G. V. J.; Brocksom, T. J.; Core structure of eremophilanes and bakkanes through niobium catalyzed Diels-Alder reaction: synthesis of ( \pm )-bakkenolide A. Journal of Organic Chemistry 2006, 71, 9880. [CrossRef] j) Lopes, C. C.; Lopes, R. S. C.; Cardoso, J. N.; Silva, J. A.; Ferreira, L. G.; Processo para a formação de hidrazidas e seus derivados a partir de hidrazinas e ácidos dicarboxílicos. BRPI 0307864-7, 2003. [Link] k) Lopes, C. C.; Lopes, R. S. C.; Cardoso, J. N.; Silva, J. A.; Ferreira, L. G.; Hydrazides and derivatives production process from hydrazines and dicarboxylic acids. WO2005/051870, 2005. (CA 143:26622) [Link]

2. a) Arpini, B. H.; Cubides-Román, D. C.; Javarini, C. L.; Araújo, M. C.; David, G. F.; Santos, R. B.; Romão, W.; Neto, A. C.; Lacerda Jr., V.; Simple niobium catalysts applied in reflux and ultrasound-assisted systems for biofuel synthesis. Journal of the Brazilian Chemical Society 2019, 30, 1897. [CrossRef] b) Website Belle Noir. Available at: <http://bellenoirmag.blogspot. com/2012_05_01_archive.html>. Accessed on: 01 December 2020. c) Website Wikimedia. Available at: <https://commons. wikimedia.org/wiki/File:Creative-Tail-Objects-gas-station.svg>. Accessed: 01 December 2020.

3. a) Bassan, I. A. L.; Nascimento, D. R.; San Gil, R. A. S.; Silva, M. I. P.; Moreira, C. R.; Gonzalez, W. A.; Faro, A. C.; Onfroy, T.; Lachter, E. R.; Esterification of fatty acids with alcohols over niobium phosphate. Fuel Processing Technology 2013, 106, 619. [CrossRef] b) Aranda, D. A. G.; Gonçalves, J. A.; Peres, J. S.;
Ramos, A. L. D.; Melo, C. A. R.; Antunes, O. A. C.; Furtado, N. C.; Taft, C. A.; The use of acids, niobium oxide, and zeolite catalysts for esterification reactions. Journal of Physical Organic Chemistry 2009, 22, 709. [CrossRef]

4. a) Nishiyama, H.; Hosoya, H.; Parker, B. F.; Arnold, J.; Tsurugi, H.; Mashima, K.; Hydrodehalogenation of alkyl halides catalyzed by a trichloroniobium complex with a redox active $\alpha$-diimine ligand. Chemical Communications 2019, 55, 7247. [CrossRef] [PubMed] b) Fuchibe, K.; Ohshima, Y.; Mitomi, K.; Akiyama, T.; Low-valent niobium-catalyzed reduction of $\alpha, \alpha, \alpha$ trifluorotoluenes. Organic Letters 2007, 9, 1497. [CrossRef] [PubMed]

5. Pereira, C. C. M.; Cruz, M. H. C.; Lachter, E. R.; Liquid phase alkylation of anisole and phenol catalyzed by niobium phosphate. Journal of the Brazilian Chemical Society 2010, 21, 367. [CrossRef]

6. Pineda, A.; Lázaro, N.; Balu, A. M.; Garcia, A.; Romero, A. A.; Luque, R.; Evaluation of acid properties of mechanochemically synthesized supported niobium oxide catalysts in the alkylation of toluene. Molecular Catalysis 2020, 493, 111092. [CrossRef]

7. a) Nascimento, L. G.; Dias, I. M.; Souza, G. B. M.; DanciniPontes, I.; Fernandes, N. R. C.; Souza, P. S.; Oliveira, G. R.; Alonso, C. G.; Niobium oxides as heterogeneous catalysts for Biginelli multicomponent reaction. The Journal of Organic Chemistry 2020, 85, 11170. [CrossRef] [PubMed] b) Lima, C. G. S.; Silva, S.; Gonçalves, R. H.; Leite, E. R.; Schwab, R. S.; Corrêa, A. G.; Paixão, M. W.; Highly efficient and magnetically recoverable niobium nanocatalyst for the multicomponent Biginelli reaction. ChemCatChem 2014, 6, 3455. [CrossRef]

8. Sturt, N. R. M.; Terra, J. C. S.; Sangiorge, D. L.; Oliveira, L. C. A.; Moura, F. C. C.; Performance of niobium catalysts in a one-pot system for selective methanol conversion to dimethoxymethane under mild conditions. Fuel 2020, 262, 116417. [CrossRef]

9. Fuji, M.; Chiwata, J.; Ozaki, M.; Aratani, S.; Obora, Y.; In Situgenerated niobium-catalyzed synthesis of 3-pyrroline derivatives via Ring-Closing Metathesis reactions. ACS Omega 2018, 3, 8865. [CrossRef] [PubMed]

10. Wei, Z.; Zhang, W.; Luo, G.; Xu, F.; Mei, Y.; Cai, H.; Mono- and bis- $N$-heterocyclic carbene complexes of tantalum and niobium with high oxidation states. New Journal of Chemistry 2016, 40 , 6270. [CrossRef]

11. Mendes, S. R.; Thurow, S.; Penteado, F.; Silva, M. S.; Gariani, R. A.; Perin, G.; Lenardão, E. J.; Synthesis of bis(indolyl)methanes using ammonium niobium oxalate (ANO) as an efficient and recyclable catalyst. Green Chemistry 2015, 17, 4334. [CrossRef]

12. Wang, Z.; Bao, X.; Xu, M.; Deng, Z.; Han, Y.; Wang, N.; Direct formation of amides from carboxylic acids and amines catalyzed by niobium(V) oxalate hydrate. ChemistrySelect 2018, 3, 2599. [CrossRef]

13. Chagas, P.; Oliveira, H. S.; Mambrini, R.; Le Hyaric, M.; Almeida, M. V; Oliveira, L. C. A.; A novel hydrofobic niobium oxyhydroxide as catalyst: Selective cyclohexene oxidation to epoxide. Applied Catalysis A: General 2013, 454, 88. [CrossRef]

14. Silva, B. H. S. T; Riehl, L. O.; Santos, G. C.; Roldao, J. C.; Silva-Filho, L. C.; Solvent-free synthesis using $\mathrm{Nb}_{2} \mathrm{O}_{5}$ and 
a theoretical-experimental study of solvent effect in new rhodamine dyes. ChemistrySelect 2020, 5, 1455. [CrossRef]

15. Yamamoto, Y.; Shimizu, E.; Ban, K.; Wada, Y.; Mizusaki, T.; Yoshimura, M.; Takagi, Y.; Sawama, Y.; Sajiki, H.; Facile hydrogenative deprotection of $N$-benzyl groups using a mixed catalyst of palladium and niobic acid-on-carbon. ACS Omega 2020, 5, 2699. [CrossRef] [PubMed]

16. Lopes, O. F.; Mendonça, V. R.; Silva, F. B. F.; Paris, E. C.; Ribeiro, C.; Óxidos de nióbio: uma visão sobre a síntese do $\mathrm{Nb}_{2} \mathrm{O}_{5}$ e sua aplicação em fotocatálise heterogênea. Química Nova 2015, 38, 106. [CrossRef]

17. Website Economic Research Service. United States Department of Agriculture - USDA. Available at: <https://www.ers.usda.gov/ topics/crops/cotton-wool/cotton-sector-at-a-glance/>. Accessed: 25 November 2020.

18. Kadam, R. L.; Kim, Y.; Gaikwad, S.; Chang, M.; Tarte, N. H.; Han, S.; Catalytic decolorization of Rhodamine B, Congo Red, and Crystal Violet dyes, with a novel niobium oxide anchored molybdenum (Nb-O-Mo). Catalysts 2020, 10, 491. [CrossRef]

19. Ravishankar, T. N.; Vaz, M. O.; Ramakrishnappa, T.; Teixeira, S. R.; Dupont, J.; Ionic liquid-assisted hydrothermal synthesis of $\mathrm{Nb} / \mathrm{TiO} 2$ nanocomposites for efficient photocatalytic hydrogen production and photodecolorization of Rhodamine B under UV-visible and visible light illuminations. Materials Today Chemistry 2019, 12, 373. [CrossRef]
20. Costa, G. P.; Rafael, R. A.; Soares, J. C. S.; Gaspar, A. B.; Synthesis and characterization of $\mathrm{ZnO}-\mathrm{Nb}_{2} \mathrm{O}_{5}$ catalysts for photodegradation of bromophenol blue. Catalysis Today 2020, 344, 240. [CrossRef]

21. Santos, A. J.; Batista, L. M. B.; Martínez-Huitle, C. A.; Alves, A. P. M.; Garcia-Segura, S.; Niobium oxide catalysts as emerging material for textile wastewater reuse: photocatalytic decolorization of azo dyes. Catalysts 2019, 9, 1070. [CrossRef]

22. Rafael, R. A.; Noronha, F. B.; Gaspar, A. B.; Synthesis and Characterization of $\mathrm{Ti}-\mathrm{Nb}_{2} \mathrm{O}_{5}$ catalysts for discoloration reaction of Bromophenol Blue and Indigo Carmine Dyes. Topics in Catalysis 2020, 63, 1066. [CrossRef]

23. Carvalho, G. S. G.; Siqueira, M. M.; Nascimento, M. P.; Oliveira, M. A. L.; Amarante, G. W. $\mathrm{Nb}_{2} \mathrm{O}_{5}$ supported in mixed oxides catalyzed mineralization process of Methylene Blue. Heliyon 2020, 6, e04128. [CrossRef] [PubMed]

24. Zarrin, S.; Heshmatpour, F.; Facile preparation of new nanohybrids for enhancing photocatalytic activity toward removal of organic dyes under visible light irradiation. Journal of Physics and Chemistry of Solids 2020, 140, 109271. [CrossRef]

25. Domingues, F. S.; Geraldino, H. C. L.; Freitas, T. K. F. S.; Almeida, C. A.; Figueiredo, F. F.; Garcia, J. C.; Photocatalytic degradation of real textile wastewater using carbon black- $\mathrm{Nb}_{2} \mathrm{O}_{5}$ composite catalyst under UV/Vis irradiation. Environmental Technology 2019, 1. [CrossRef] [PubMed] 